\title{
Solution Aversion: On the Relation Between Ideology and Motivated Disbelief
}

\author{
Troy H. Campbell and Aaron C. Kay \\ Duke University
}

\begin{abstract}
There is often a curious distinction between what the scientific community and the general population believe to be true of dire scientific issues, and this skepticism tends to vary markedly across groups. For instance, in the case of climate change, Republicans (conservatives) are especially skeptical of the relevant science, particularly when they are compared with Democrats (liberals). What causes such radical group differences? We suggest, as have previous accounts, that this phenomenon is often motivated. However, the source of this motivation is not necessarily an aversion to the problem, per se, but an aversion to the solutions associated with the problem. This difference in underlying process holds important implications for understanding, predicting, and influencing motivated skepticism. In 4 studies, we tested this solution aversion explanation for why people are often so divided over evidence and why this divide often occurs so saliently across political party lines. Studies 1, 2, and 3-using correlational and experimental methodologies-demonstrated that Republicans' increased skepticism toward environmental sciences may be partly attributable to a conflict between specific ideological values and the most popularly discussed environmental solutions. Study 4 found that, in a different domain (crime), those holding a more liberal ideology (support for gun control) also show skepticism motivated by solution aversion.
\end{abstract}

This article may not exactly replicate the final version published in the APA journal. It is not the copy of record.

Many serious local, national, and global problems exist today. For instance, physical and social scientists have identified environmental problems such as climate change, rising crime rates, and emerging health epidemics as requiring immediate, proactive intervention. However, even in cases in which there is little scientific debate, substantial skepticism exists in the general populace, with experiments and polling data showing that groups of people vary widely in the degree to which they dispute these facts (Pew Research Center, 2010; Schuldt, Konrath, \& Schwarz, 2011).

Why do some people, in some domains, appear so especially distrustful of conclusions that scientists themselves agree upon? Several interesting perspectives have been offered to help explain patterns of scientific denial, including heightened sensitivity to negative information (Carraro, Castelli, \& Macchiella, 2011; Oxley et al., 2008), dispositional motivated cognition differences (Jost, Glaser, Kruglanski, \& Sulloway, 2003), and conspiratorial mindsets (Lewandowsky, Gignac, \& Oberauer, 2013). Without disputing any of these approaches, we seek to offer a novel

Troy H. Campbell, Fuqua School of Business, Duke University; Aaron C. Kay, Fuqua School of Business and Department of Psychology and Neuroscience, Duke University.

Parts of this article were presented at the annual conferences of the Society for Consumer Psychology and the Society for Personality and Social Psychology. Rachel Anderson, Katie Becker, Michael Bleggi, Tyler Fredricks, Wookin Kim, Minn Htet Kine, Shannon Lin, and Thomas Vosburg served as research assistants on this project.

Correspondence concerning this article should be addressed to Aaron C. Kay, Duke University, Fuqua School of Business, 100 Fuqua Drive, Durham, NC 27708. E-mail: aaron.kay@ duke.edu perspective on denial that can complement this newly burgeoning and important psychological literature.

We propose a motivation behind the denial of many of today's problems that is rooted not in a fear of the general problem, per se, but rather in fear of the specific solutions associated with that problem. Building on and integrating the growing literatures addressing the psychology of ideological motivations (Carney, Jost, Gosling, \& Potter, 2008; Jost, 2006; Jost, Nosek, \& Gosling, 2008; Kahan, 2009; Taber \& Lodge, 2006; Tedin, 1987), identity motives (Sedikides \& Strube, 1997), and motivated cognition (Ditto \& Lopez, 1992; Kunda, 1990), we propose a solution aversion model to explain why people are often so divided over scientific evidence about certain problems and why this divide often occurs across political party lines (McCright \& Dunlap, 2011a, 2011b; Pew Research Center, 2010; Schuldt et al., 2011). The solution aversion model predicts that certain solutions associated with problems (e.g., government regulation) are more aversive and more threatening to individuals who hold an ideology that is incompatible with or even challenged by the solution, and this increases skepticism of the problems' existence. Through three experiments, we provide evidence for this model and do so in one of the most politically contentious and arguably important problems of modern times: environmental degradation and climate change. We provide an additional study outside this area to show the breadth of the model.

\section{Climate Change and the Environment}

In the scientific community, there is a consensus (Cook et al., 2013; Intergovernmental Panel on Climate Change, 2007; Oreskes, 2004) that global temperatures will rise over the next century, that 
temperature increases will be consequential, and that humankind is largely responsible for climate change (and humankind is also the cause of other environment risks, such as lung damage; State of the Air, 2013). However, there is a near political party-line divide over the veracity of many of the same issues. In the United States, Democrats (liberals) tend to agree with the consensus of the scientific community on climate change, and Republicans (conservatives) more often hold the belief that temperatures will not increase and that humankind is not responsible (McCright \& Dunlap, 2011a, 2011b; Pew Research Center, 2010; Schuldt et al., 2011). Researchers, media outlets, bloggers, and politicians propose many explanations for this party-line divide. Some propose a differential exposure hypothesis, stating that Republicans and Democrats differ in exposure to scientific information supporting the veracity of climate change, for example, through exposure to different media outlets or educational systems (Yam, 2012). Others propose a differential faith in science hypothesis, which posits that Republicans simply have less faith in science or are even "antiscience" (Cunningham, 2012; Gauchat, 2012). Some other research supports the possibility that Republicans' cognitions are more motivated and threatened (Jost et al., 2003) by negative information (Carraro et al., 2011; Oxley et al., 2008) than are those of Democrats, making Republicans more likely to deny the existence of negative issues like climate change or dangerous chemicals in the air. Finally, many vocal Republicans claim they have uniquely evaluated climate change science thoughtfully and have rationally concluded it does not exist (Samuelson, 2010).

Though the general skepticism and political divide over climate change cannot be reduced to a single cause, it is clear that strategies of communication intended to persuade all Americans of the scientific consensus around climate change and other environmental dangers have failed to successfully address the causal factors. Over the past two decades, media vehicles (e.g., An Inconvenient Truth) entailing an onslaught of statistics and proposals for serious governmental regulatory policies (Gore, 2006) have both dominated environmental communication and failed to resonate with conservatives (Kahan, 2010). The political divide has persisted despite such a staggering and often aggressive amount of environmental communication, which begs the question of what specific causal factor or factors can explain the divide and improve environmental communication to reduce the divide.

\section{Motivated Skepticism}

Logically, one's belief in the accuracy of a scientific finding should be independent of whether the findings and related consequences are undesirable. Yet, research in motivated reasoning shows that psychological motivations often direct reasoning, such that judgments of evidence are not independent of desires or motivations (Ditto \& Lopez, 1992; Kunda, 1990). Of importance, recent evidence has demonstrated that political ideology (Tedin, 1987 , p. 65, cited by Jost, 2006, p. 653), defined as "an interrelated set of moral and political attitudes that possesses cognitive, affective, and motivational components," can similarly guide, funnel, and constrain the processing of information and alter behavior (Carney et al., 2008; Jost, Nosek, \& Gosling, 2008; Kahan, 2009; Taber \& Lodge, 2006). Such motivated biases in cognition and behavior can occur for those holding conservative or liberal ideologies, depending on how the circumstances threaten or support one's respective ideologies and intuitions (Ditto \& Liu, 2011; Haidt, 2013).

Some researchers have posited that conservatives are dispositionally more prone to motivated cognition (Jost et al., 2003). Some findings suggest in particular that conservatives have a greater sensitivity to fearful and negative information that may lead to motivational differences in cognition (Carraro et al., 2011; Oxley et al., 2008). This would suggest that conservatives are more motivated to deny climate change science due to a stronger fear of the problem's negative consequences. In this paper, we do not seek to support or refute these findings; that is, our purpose here is not to locate something unique to the psychology of conservatives that makes them more likely to deny threatening scientific fact or something unique to liberals that make them more likely to accept it. Instead, we focus on how a basic model of motivated cognition - one that should apply to all sorts of people - that can be used to shed new light on this particular ideological divide. Thus, though a consequence of testing our solution aversion model in the context of climate change and the environment is that a good portion of our theory and evidence will be directed toward explaining conservatives' relatively low level of acceptance, the analysis presented here is not meant to apply to one specific group. Indeed, to make this point clear, in our final study we shift the context away from the environment and demonstrate that individuals holding a more liberal ideology will also engage in solution aversion.

\section{Fear of the Problem or Fear of the Solution?}

Public problems often morally mandate policy solutions. Accordingly, the call to politicized action tends to closely follow the scientific dialogue around any large-scale problem (Gore, 2006; see Thaler \& Sunstein, 2008, for an example of social science problems followed by social science policy recommendations). For instance, research on education is often paired with policy solutions such as heavy teaching requirements, research on human irrationality is often coupled with proposals for governmental interventions, and climate change research is often tied to proposals that restrict free markets and incur certain proximal costs (Babiker \& Eckaus, 2002; Koba, 2013).

We hypothesize that one important consequence of this is that the solutions that are often paired with these issues may motivate reactions to the science. That is, although it may be tempting to assume people's reactions to reports of potentially severe societal threats (e.g., environmental health risks, crime) may be driven simply by people's fear of falling victim to those threats, the reality may be more complicated. That is, people may deny problems not because of the inherent seriousness of the problems themselves but because of the ideological or tangible threat posed by the associated policy solutions.

It has become increasingly clear that political ideologies and affiliations are not just objectively adopted beliefs but are deeply ingrained aspects of social identity (Abramowitz \& Saunders, 2006; Greene, 2004; Toner, Leary, Asher, \& Jongman-Sereno, 2013). As with other social-identity processes, ideology can powerfully motivate perceptual and interpretive processes (Jost, 2006). As a result, although certain scientific realities-like climate change - may not in and of themselves threaten a specific identity or ideology, consistently pairing them with specific policy solu- 
tions might lead perceivers to act as though they do. This is important insofar as it suggests that debates that appear to be about scientific evidence may instead be fueled by something entirely unrelated to the veracity of the science: the policies most commonly proposed as the solution. Moreover, to the extent this is so, it suggests that the solution to scientific skepticism-especially skepticism that is found among politicians and citizens but is almost entirely absent from the scientific community (Cook et al., 2013) - is not to simply present the public with more or better data but to consider other motivating factors. Over the past decade, the main strategy to reduce climate change and environmental skepticism has often been an "education only" strategy that has paid little attention to ideological concerns.

The solution aversion model proposed here predicts that people will be skeptical of scientific evidence supporting the existence of a problem, to the degree that the existence of the problem directly implies solutions that threaten a person's cherished beliefs and ideological motives (Jost, 2006; Lord, Ross, \& Lepper, 1979). When located in the context of climate change and debates over the science surrounding it, this framework predicts that the denial of scientific evidence will vary across people, specifically along ideological lines, to the extent the proposed solution to the scientific problem is discordant with ideological positions.

The most commonly discussed policy solutions to climate change have overwhelmingly been pollution taxes, emissions restrictions, and general governmental intervention (Greenpeace, 2011; Hansen, Stiglitz, Pachauri, \& Rosenzweig, 2008; Koba, 2013). In the media, government policies that curtail unregulated businesses that operate and pollute in a free market are presented as the most important steps in solving climate change (Cutting, 2013). These restrictive government policies contradict the ideologies of many Republicans; in particular, ideological beliefs in the efficacy of free markets and limited government regulation (GOP.com, 2014; Jost et al., 2003; Platform Committee, 2012). The principle of free markets and limited government intervention is an important (if not the most important) ideological principle to many Republicans. Prominent conservative Republicans recently demonstrated their commitment to free markets through their willingness to force the government of the United States into a shutdown in October 2013 over the Affordable Care Act-a policy that restricts free markets in certain ways (Narula, Jacobs, \& Ohikuare, 2013). In contrast, for Democrats, free market concerns are far less important and may at times even be contradictory to some Democrats' ideologies. In general, then, for Republicans but not for Democrats, the popular conception of climate change may threaten the general merits of their political ideology as a guide to societal success. As such, Republicans may be motivated to deny climate change and other environmental problems in order to deny the implications that the existence of such problems holds for their ideological values.

The current work tests this notion experimentally. According to a solution aversion perspective, Republicans' skepticism of climate change is motivated not solely by sensitivity to threat and danger, as other perspectives suggest (Carraro et al., 2011; Jost et al., 2003; Oxley et al., 2008), but also by the salient policy solutions. To the extent this is so, we should observe that Republicans' belief in the veracity of environmental science should be (a) especially dependent on Republicans' perceptions of the popularly discussed policy consequences associated with environmental problems and (b) dependent on how strongly individual Republicans hold specific ideological beliefs that are challenged by these policies (such as faith in the free market). This model also leads to the prediction that if solutions to some societal issue (e.g., crime) strongly threatened an important ideological value held by Democrats or those with a more liberal stance (e.g., strongly restricting gun ownership), these individuals would show similar ideologically motivated skepticism of the associated problem. By manipulating the various policy implications associated with problems and measuring acceptance of the science and belief in severity of problems, we tested these hypotheses across four studies.

The first two studies focused on climate change. In these two studies we presented all participants with the Intergovernmental Panel on Climate Change's 2007 estimate that global temperatures will rise by approximately 3.2 degrees Fahrenheit in the $21 \mathrm{st}$ century and that humans are in large part the causal agent (this statistic represents a lower estimate by the Intergovernmental Panel on Climate Change, 2007). We used participants' own subsequent estimation of the number of degrees that they believe temperatures will rise in the 21 st century to measure agreement with climate change science (as well as a general Likert scale measure typical of past research). This numeric-dependent measure allowed us to assess on a more granular level how Democrats and Republicans are interpreting the specific climate statistics, as opposed to other issues intertwined with the statistic, such as general beliefs about the importance of the environment or humankind's role in affecting climate change (Feinberg \& Willer, 2011; Feygina, Jost, \& Goldsmith, 2010; McCright \& Dunlap, 2011b). In Study 1, we used a correlational design to examine how Republicans' and Democrats' beliefs about the economic impact of climate change solutions relate to their beliefs about climate change science. In Study 2, we used these correlational insights to inform an experimental design that manipulates the types of policies ostensibly being proposed to address climate science (i.e., ones that are more and less compatible with a free market ideology) and then examined how these manipulated policy implications of climate change influence Republicans' and Democrats' interpretations of the climate science statistic. In Study 3, we more closely examined how individual differences in attachment to free market ideology among Republicans influence skepticism toward an environmental issue.

Finally, in Study 4, we looked at a separate issue (crime) with a different ideology (attitudes toward gun rights) and assessed people's feelings about the severity of the problem rather than judgments about scientific fact. This allowed us to better test the breadth of the model and to examine a situation where those with a more liberal stance might show skepticism that fits a solution aversion perspective.

\section{Study 1}

We have suggested that the political party divide in skepticism toward climate science is at least partly due to the political policy discussion surrounding climate change that generally proposes policy solutions unfriendly to Republican ideology (Hansen et al., 2008; Koba, 2013) but not unfriendly to Democratic ideology. In Study 1, we tested this hypothesis correlationally.

We surveyed Republicans and Democrats taken from an online sample who had previously indicated their political status. This 
allowed us to preselect on party without making party salient in the design itself. We measured (a) their beliefs about climate change science, (b) their beliefs about the impact of climate change solutions on the economy, and (c) the strength of their belief in a free market ideology.

This design allowed us to offer an initial test of whether differences in ideological concerns are related to differences in climate change belief. We were particularly interested in testing whether differences in beliefs about climate changes were mediated by differences in concerns about the impact of climate change solutions on the economy. ${ }^{1}$

\section{Method}

Participants. One hundred and eighty-nine participants were recruited online for a short survey using Qualtrics samples $\begin{array}{llll}\text { (male } \quad 72 \text {, female } \quad 117 ; M_{\text {age }} & 44.31 \text { years, } S D & 16.50) \text { and }\end{array}$ were paid $\$ 0.75$. Participants were recruited on the basis of previously reported affiliation as Republican $(N \quad 95)$ or Democrat ( $N$ 94) to Qualtrics. In all studies reported, participants were excluded prior to entry into the main survey if they had already taken an online survey on the topic with our lab, had failed an attention check, or had the same Internet protocol (IP) address as a prior participant.

Materials and procedure. In this and all studies, all relevant measures administered are described and reported. Participants first answered a number of filler questions, such as television preferences, that were meant to be irrelevant. Next, participants were presented with the Intergovernmental Panel on Climate Change statistic, which read, "The Intergovernmental Panel on Climate Change (IPCC) reported that there would be an increase of 3.2 degrees Fahrenheit in worldwide temperatures in the $21 \mathrm{st}$ century and that humans are responsible for global climate change patterns." We then administered two measures of belief in climate change, one dichotomous and one continuous.

First, participants were asked, "If nothing is done by humans with regard to the environment, how many degrees do you think global temperatures will rise in this century?" and were told to write down a number of degrees Fahrenheit. We classified people as disagreeing if they estimated that temperatures would rise less than the IPCC suggested (lower than 3.0) and as agreeing if they estimated anything at or beyond the IPCC statistic. This agreement measure used self-reported temperature estimates to provide a straightforward measure of agreement versus disagreement with science that supports the existence of climate change. Coding this as a linear measure, in which lower numbers are assumed to indicate more skepticism toward climate change (or higher numbers are assumed to indicate more acceptance), was not feasible because there is a nonlinear relationship between the numbers on the scale and agreement with the science; that is, the distinction between two estimates of, say, 3.5 and 4.5 or 1.5 and 2.5 is much less meaningful than the distinction between two estimates of 2.5 and 3.5 (even though all pairs involve a difference of 1 degree). This is because the latter pair involves moving across the actual number offered by IPCC, but the first two pairs do not. Coding disagreement continuously as an absolute value away from, say, 3.0 degrees also does not work because this leaves a large asymmetry in range of responses in the two directions.
There was initially some question as to whether to use the number 3.0 or 3.2 as the cutoff for agreement versus disagreement with climate change science. Whereas the second author had assumed we would use 3.2, the first author assumed 3.0 was the correct number. The case for using the number 3.2 was that it was the exact number offered by the IPCC. The case against it was that eliminating those who offered the number 3 was eliminating those who were agreeing and just rounding to a nearly identical whole number, which seemed feasible. Ultimately, after we crosschecked people's responses on the estimate measure with their responses to conceptually similar continuous measures of climate science agreement that were also included (one in Study 1 and two in Study 2), it became obvious that 3.0 was the most appropriate cutoff. Indeed, every analysis we conducted to examine whether 3.0 was the most appropriate cutoff for belief in climate change suggested it best distinguished between agreement and disagreement. $^{2}$ In Study 2, for example, we added a continuous scale intended to measure agreement with the climate change science presented. Tellingly, no significant differences on this alternative measure were found between those who estimated temperature increases of 3.0, 3.2, or higher on the degree estimate measure, but all three of these groups differed from those reporting an estimate of 2.9 or below. In the present study (i.e., Study 1), we did not have that continuous agreement measure to cross-check our coding scheme with, but we did have a continuous measure of belief that humans were causing climate change. Looking at responses to that measure as a function of people's temperature estimates revealed the identical pattern: Those who indicated temperature increases of 3.0, 3.2, or above 3.2 did not differ from one another, but all three of those groups were significantly higher in belief than those reporting an estimate of 2.9 or below.

Because this dichotomous measure sacrifices our ability to conduct continuous analyses and does not capture beliefs about whether humankind has played a role in climate change (a belief

\footnotetext{
${ }^{1}$ It is important to note that we did not claim that this model would explain all the variance in climate change beliefs, for two reasons. First, our measures, like any measure, are limited in capturing the true effect. Second, other processes (differential exposure, faith in science, fear reactivity, party-line stances) certainly explain some of the variance in the political climate change divide. The solution aversion model is not a mutually exclusive hypothesis.

${ }^{2}$ To check whether our coding scheme made sense, we coded participants at one of four degree estimate levels: L1, below 3.0; L2, at 3.0; L3, at 3.2; or L4, above 3.2. No participant indicated a number between 3.0 and 3.2. We then conducted a one-way analysis of variance using these 4 levels as the predictor variable and participant responses on the continuous measure of humans causing climate change in Study 1 and separately in Study 2 . This revealed significant models, $F_{\text {Study } 1}(1,185) \quad 10.58, p$ $.001, F_{\text {Study 2 }}(1,117) \quad 11.88, p \quad .001$, such that in their respective studies participants at L1 showed a significantly lower climate change belief on the continuous measure than did those at any of the other levels (individual contrast tests, $\left.p \mathrm{~s}_{\text {Study } 1} .004, p \mathrm{~s}_{\text {Study } 2} \quad .001\right)$. None of the other levels showed a significant difference among themselves ( $p \mathrm{~s}_{\text {Study }} 1$ $.418, p \mathrm{~s}_{\text {Study } 2} .703$ ), including the key comparison between L2 and L3, indicating that 3.0 and 3.2 indicated similar agreement with the climate change science. Next, we conducted the same analysis but with the continuous variable measuring agreement with the IPCC statistic that was added to Study 2 to test our assumptions. This revealed a similar significant model, $F(1,117) \quad 31.85, p \quad .001$, such that participants at L1 showed a significantly lower agreement than did those at any of the other levels (individual contrast tests, $p \mathrm{~s} \quad .001$ ), but none of the other levels differed from each other ( $p$.389).
} 
that other research on climate change has used as a proxy of denial because it is considered of particular importance in motivating collective action, Krosnick, Holbrook, Lowe, \& Visser, 2006), the next screen presented participants with the aforementioned question asking them whether they agree that humans have played a role in causing climate change. Responses to this item were given on an 8-point scale anchored at No chance that humans are causing global climate change and Humans are certainly causing global climate change.

Next, we assessed how participants felt climate change solutions would impact the economy. Participants read, "There are a few popular solutions that have been proposed to reduce climate change. If these solutions were passed into law, what kind of effect do you think these solutions would have on the American economy?" Participants answered on 7-point scale anchor at 3 (Have a strong NEGATIVE effect on the American economy) to 3 (Have a strong POSITIVE effect on the American economy). This question referred only to "solutions." Not mentioning any specific solutions allowed us to test whether, without our interference, Republicans (more than Democrats) naturally associated negative economic impact more with climate change solutions. Therefore, this experiment provides evidence for an organically occurring solution aversion effect on the part of Republicans, rather than the experimentally induced solution aversion effects that are tested later in the paper.

Finally, on a separate screen, all participants read a passage about the free market, which stated,

When the government does not interfere with the economy it creates what is known as the "Free Market." Free Markets are called "free" because they are free of governmental regulation. Making markets more free is the foundation of the conservative (Republican) economic philosophy. The United States founding fathers created the United States as a Free Market Nation.

They then were asked to indicate (a) how much they agreed with the statement "The Free Market makes a country great" and (b) how much they supported free market ideology on unmarked sliding point scales (each question's scale had 101 distinct points). These two items were averaged and were used as a measure of endorsement of free market ideology $\left(\begin{array}{lll}r & .87, p & .001, M\end{array}\right.$ 70.47, SD 25.38).

\section{Results}

Difference in party beliefs. In a result replicating the past decade of survey polling data (McCright \& Dunlap, 2011a, 2011b; Pew Research Center, 2010; Schuldt et al., 2011), Republicans were more skeptical of climate change science than were Democrats. This was observed on both dependent measures. On the dichotomous agreement measure, Republicans were less likely to agree with the climate change science than were Democrats; respectively, $60 \%$ agreement and $80.85 \%$ agreement, ${ }^{2}(1, N$

189) $9.85, p \quad .002$. On the continuous likelihood measure of human causation, Republicans were less likely to indicate humankind was causing global climate change than were Democrats; respectively, $M \quad 4.83, S D \quad 1.19$ and $M \quad 6.49, S D \quad 1.54$, $t(187) \quad 6.55, p \quad .001$.

Also as predicted, Republicans reported that the solutions to climate change would have a more negative effect on the economy than did Democrats; respectively, $M \quad 0.42, S D \quad 1.83$ and $M \quad 0.55, S D \quad 1.80, t(187) \quad 4.06, p \quad .001$. Republicans also reported stronger endorsement of free market ideology than did Democrats; respectively, $M \quad 82.24, S D \quad 18.48$ and $M \quad 58.59$, $S D \quad 25.95, t(187) \quad 7.22, p \quad .001$.

Mediation: Effect of economic beliefs on climate change between parties. Next we tested whether the difference between Republicans' and Democrats' belief in climate science was mediated by their different beliefs about the impact of climate change solutions on the economy. Two separate analyses were conducted with each of the two climate changes measures: the likelihood of human causation measure and the agreement measure. A simple mediation bootstrapping procedure (Preacher, Rucker, \& Hayes, 2007) in a PROCESS SPSS macro (Model 4; 5,000 bootstraps; Hayes, 2012), with Democrats coded as 1 and Republicans coded as 0 , revealed a significant indirect effect of political affiliation on both measures of climate change beliefs through beliefs about economic impact: likelihood that humans are the cause measure, $b \quad .35, S E \quad .13,95 \%$ CI [.157, .657]; dichotomous agreement with climate change science measure, $b \quad .39, S E \quad .16,95 \%$ CI $[150, .770]$.

\section{Discussion}

Together, these correlational and mediation findings support the hypothesis that beliefs about the impact of climate science solutions (for the economy, in particular) are linked to Republicans' beliefs about climate change science and may in fact drive their increased skepticism when compared to Democrats. That is, Republicans more than Democrats see climate change solutions as a greater threat to the economy, and Republicans' economic beliefs about climate change policies mediate their skepticism of climate change science. At the same time, these results are correlational, and so caution must be exercised when making any conclusions about causality. To hone in on causality, Study 2 shifted to an experimental paradigm.

\section{Study 2}

If the policy implications of climate change truly are a causal mechanism of Republicans' skepticism toward climate science, as Study 1 suggests, we should observe an abated skepticism among Republicans when we directly manipulate the nature of the solutions to be less inconsistent with their values.

To this end, in Study 2 we varied the policy solutions we paired with the IPCC statistic. Half of the participants read about one of the most popularly discussed solutions to climate change: a regulatory restrictive emissions policy. This policy should be very unfriendly to Republican ideology but friendly to Democratic ideology. The other participants read about a free market friendly solution that involved the United States profiting from green technology, a policy that should be friendly to both parties' ideology. We predicted that Republicans would be more likely to agree with climate science when the policy was free market friendly than when it involved government regulation. For Democrats, however, we expected agreement with climate science to be relatively similar across the two policy solutions. Further, we predicted that the changes in Republican skepticism would be mediated by changes in Republican participants' views that the 
climate change solutions threaten the economy. This experimental design (that includes mediation) offers an especially rigorous test of the solution aversion model.

\section{Method}

Participants. In this experiment and the following two experiments, we used a different recruitment database (Amazon Mechanical Turk). In this study, we did not ask for political affiliation in a separate pretest phase and simply recruited equal numbers of Republicans and Democrats on the basis of a predetermined sample size. Party was assessed at the end the study. Our goal was for 20 participants per cell, but knowing Amazon Mechanical Turk is overrepresented with Democrats, we assumed we would need to oversample to ensure enough Republicans (i.e., rather than recruit 80 participants and assume 40 of each party would be represented in the sample, we needed to recruit toward a target of 120 to obtain a minimum of 40 per party). This method led to an imbalance in the number of Republican and Democrat participants but still resulted in statistically sufficient numbers of both. Of the 121 participants (male $\quad 52$, female $\quad 69 ; M_{\text {age }} 35.06$ years, $S D$ 14.21) on Amazon Mechanical Turk who completed our experiment and reported affiliation with one of the two target parties, 81 self-reported as Democrats and 40 self-reported as Republicans. This left us with the target number of 20 participants per experimental condition. Persons who reported they were independent/not affiliated ( $n$ 39) were not analyzed. Condition did not influence self-reported party affiliation. Participants were paid $\$ 0.45$.

Materials and procedure. Participants were randomly assigned to one of two current event conditions (full stimuli are available in the online supplemental materials). Both current events recounted quotes from a speech we created about climate change, in which the speaker cited the complete IPCC statistic statement. In the free market friendly condition, the speaker described how the United States could help stop climate change and profit from leading the world in green technology. In the government regulation condition, the speaker described how the United States could help stop climate change and lead the world in restrictive emissions policies.

Participants then answered the two belief in climate science items from Study 1 (i.e., the dichotomized temperature estimate item and the continuous item asking about the human role) and, as a manipulation check and potential mediator, the item from Study 1 that measured beliefs that climate change solutions will negatively impact the economy.

Three new dependent variables were added in this experiment. The first new dependent variable - described in Study 1-asked participants to indicate how much they agreed with the 3.2 estimate on a 7-point agreement scale from Strongly Disagree to Strongly Agree. This measure was included specifically to ensure that the dichotomous coding scheme used in Study 1 and again here - in which we place our cutoff for agreement as 3.0 rather than 3.2-was reasonable. Note that this measure does not serve as a feasible continuous measure of whether someone believes climate change is in fact happening but only as an indicator of whether someone agrees with the specific IPCC statistic. This is because those who indicate "disagree" on that particular scale might do so for two reasons: either because they think climate change is real but the actual number is higher or because they do not believe in climate change. As a result, we could not use this indicator in our main analyses.

The second new dependent variable was the integrated beliefs measure. We asked participants which statement from the following list best characterized their opinion: (a) Climate change is real, humans are causing it, and humans can fix it; (b) Climate change is real, humans are causing it, and humans cannot fix it; (c) Climate change is real, humans are not causing it, and humans can fix it; (d) Climate change is real, humans are not causing it, and humans cannot fix it; (e) Climate change is not real. This measure allowed us to test three beliefs in conjunction: the belief that climate change exists, the belief humans are causing climate change, and the belief humans can fix it - and different combinations of these. This variable also served as a more straightforward measure of denial of humankind caused climate change.

The third new dependent variable was intended to be a broader version of the economic impact of the solution question. This favorable-solution measure asked participants to complete the statement "The proposed solutions to climate change are . .." on a 7-point scale from 3 (Very Bad Ideas) to 3 (Very Good Ideas).

Participants responded to the measures in the following order: the dichotomous agreement with climate change science measure, the continuous agreement with the IPCC statistic measure, the likelihood humans are causing climate change measure, the integrated belief measure, the problems measure, and the economy measure.

\section{Results}

Manipulation check. First, it was necessary to ensure that our manipulation of policy solutions did in fact make the solutions less threatening to core ideological values of Republicans. To this end, we conducted a 2 (party: Democrat vs. Republican) 2 (policy solutions: government regulation vs. free market friendly) analysis of variance (ANOVA) on the measure gauging participants' feelings about how the policy would impact the economy. There was a significant main effect of party affiliation, such that Democrats

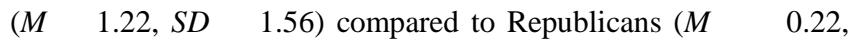
$S D$ 2.11) reported more positive beliefs about the effect of the climate solutions on the economy, $F(1,117) \quad 23.41, p \quad .001$,

2 .14. There was a significant main effect of solution, such that those who saw the free market friendly solution $(M \quad 1.24, S D$ 1.54) compared to those who saw the government regulatory solution $\left(\begin{array}{lll}M & 0.15, S D & 2.08\end{array}\right)$ reported more positive beliefs about the impact of climate solutions on the economy, $F(1,117)$ $19.20, p \quad .001,2 \quad .115$. This analysis also revealed the predicted interactive pattern, $F(1,117) \quad 6.84, p \quad .01, \quad{ }^{2} \quad .06$. Republicans were much more likely to say solutions would relatively improve the economy when the solutions were presented as free market policy $(M \quad 0.77, S D \quad 1.78)$ than when they were presented as regulatory policy $(M \quad 1.44, S D \quad 1.85), F(1$, 117) $7.31, p \quad .008,{ }_{2}^{2} \quad .156$. Democrats' beliefs about economic impact, on the other hand, did not significantly vary across condition and were generally positive: free market friendly policy, $M \quad 1.48, S D \quad 1.37$; regulatory policy, $M \quad 0.92, S D$ $1.72, F(1,117) \quad 2.35, p \quad .128,{ }^{2} \quad .020$.

Continuous measure of likelihood of the human role. We conducted a 2 (party: Democrat vs. Republican) 2 (policy solutions: government regulation vs. free market friendly) 
ANOVA on the measure of the human causal role. There was a significant main effect of party affiliation, such that Democrats (M 6.70, SD 1.28) compared to Republicans (M 4.77, $S D$ 2.09) reported strong beliefs in the likelihood of human causation, $F(1,117) \quad 48.58, p \quad .001, \quad 2 \quad .255$, and a significant main effect of solution, such that those who saw the free market friendly solution $\left(\begin{array}{lll}M & 6.45, S D & 1.68\end{array}\right)$ compared to those who saw the government regulation solution $(M \quad 5.60$, $S D$ 1.90) reported stronger beliefs in the likelihood of human causation, $F(1,117) \quad 16.01, p \quad .001, \quad 2 \quad .084$.

Of importance, the analysis also revealed the predicted interactive pattern, $F(1,117) \quad 8.78, p \quad .004, \quad 2 \quad .05$ (see Figure 1). To explore this interaction, we tested the effect of policy solutions separately for each party. Self-identified Republicans reported significantly higher belief in the human role when the policy solution was free market friendly $\left(\begin{array}{lll}M & 5.68, S D & 2.08\end{array}\right)$ than when the policy involved governmental regulation $(M \quad 3.67$, SD $\quad 1.53), F(1,117) \quad 18.10, p \quad .001, \quad 2 \quad .10$. Self-identified Democrats' belief in the human role did not vary significantly across policy solutions, $F(1,117) \quad 0.53, p \quad .467, \quad 2 \quad .003$ $\left(M_{\text {free market friendly }} \quad 6.84, S D \quad 1.31 ; M_{\text {government regulation }}\right.$ 6.54, SD 1.24).

With the same dependent measure, we also examined the hypothesis that the political divide over climate change would be more pronounced with the government regulatory solution and would be attenuated (or eliminated) with the free market friendly solution. As hypothesized, the political divide over climate change was affected by the policy solution, such that self-identified Democrats were more likely than self-identified Republicans to believe that humans were causing climate change when the policy solution was governmental regulation, $F(1,117) \quad 45.03, p \quad .001,2$ .24 , but this difference was attenuated (though still significant) when the policy was free market friendly, $F(1,117) \quad 8.87, p$ $.004,{ }^{2} 0.05$.

Dichotomous measure of (dis)agreement. Next, we conducted a binary logistic regression of dichotomous measure of agreement with climate change science (i.e., the dependent measure employed in Study 1) on party, policy solution, and their interaction. As shown in Figure 2, the model revealed the predicted interactive pattern, $b \quad 1.41$, Wald ${ }^{2}(1) \quad 2.70, p \quad .10$, though, in this case, the overall interaction term did not reach full significance. However, because the thrust of our prediction is about the simple effects (i.e., that Republicans but not Democrats will be affected by the manipulation) and the pattern is identical to the other significant interaction effects reported across all our studies, we examined the simple effects of policy solution for Republicans and Democrats separately. Exploring the interaction revealed results that mirrored those observed with the continuous measure. Self-identified Republicans reported significantly higher rates of agreement with the climate change science when the policy solution was free market friendly $(55 \%)$ than when the policy was governmental regulation $(22 \%),{ }^{2}(1, N \quad 40) \quad 4.31, p \quad .038$. However, self-identified Democrats' rates of agreement did not significantly depend on whether the policy solution was free market friendly $(68 \%)$ or governmental regulation $(68 \%),{ }^{2}(1, N \quad 81) \quad .003, p \quad .953$. Also, as hypothesized, the political divide over climate change was affected by the policy, such that Republicans were more likely than Democrats to disagree with climate science when the policy solution was governmental regulation, ${ }^{2}\left(\begin{array}{llll}1, N & 55\end{array}\right) \quad 10.0, p \quad .002$, but this divide was reduced when the policy was free market friendly, ${ }^{2}(1, N \quad 66) \quad 1.18, p \quad .278$.

Moderated mediation. Finally, we assessed whether the significant interaction between political affiliation (Republican vs. Democrat) and solution (free market vs. government regulation) on climate change beliefs was mediated by differing views about how these solutions would impact the economy. To test this hypothesis, we conducted a moderated mediation bootstrapping procedure (Preacher et al., 2007) in a PROCESS SPSS macro (5,000 bootstraps; Hayes, 2012, Model 8), with the government regulatory solution coded as 1 and the free market solution coded as 0 . We tested the indirect effect of policy solution on climate change beliefs through beliefs that the economy would be impacted by climate change solutions, conditional on political affiliation. Two separate analyses were conducted with each of the two climate changes belief measures: the continuous likelihood of human causation measure and the dichotomous agreement measure.

For Republicans, we observed a significant indirect effect of climate change policy through opinions regarding the economic

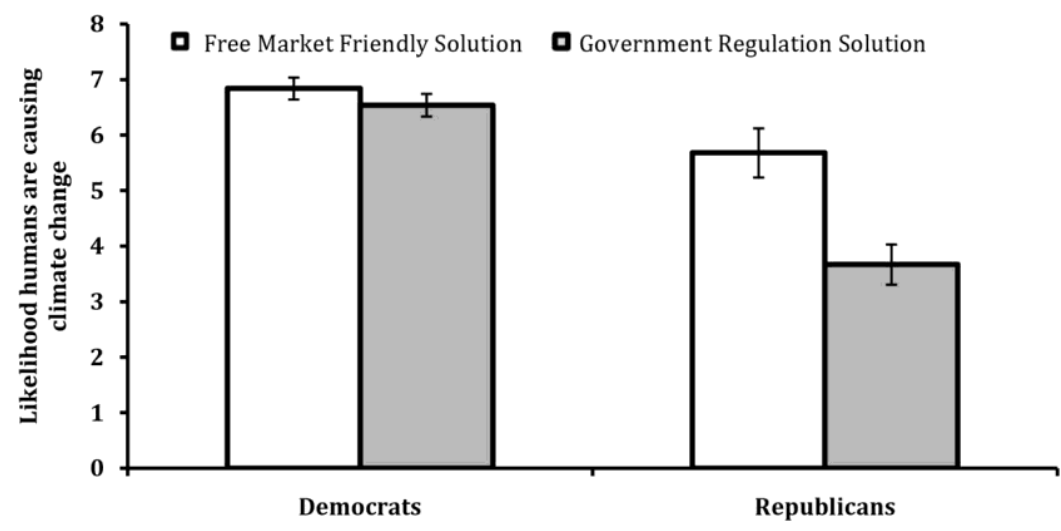

Figure 1. Likelihood that humans are causing climate change by self-reported political party affiliation and proposed policy solution (Study 2). All bars are significantly different ( $p$ s .05) from one another except for the two Democrats bars. Error bars reflect the estimated least squared standard errors. 


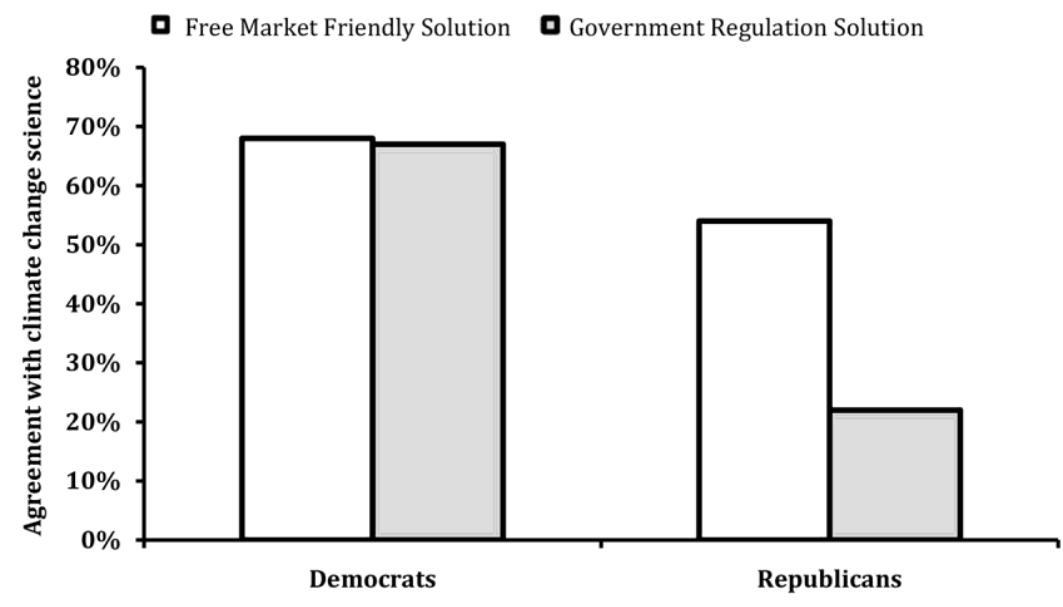

Figure 2. Agreement with climate change science as a function of self-reported political party affiliation and proposed policy solutions (Study 2). Agreement was measured dichotomously as indicating a value of 3.0 degrees or higher versus not. The first three bars are individually significantly different from the last bar (the Republicans in government regulation solution; $p \mathrm{~s}$.05). There are no other significant differences.

impact of climate change solutions for both measures of skepticism toward climate science: likelihood that humans are the cause measure, $b \quad 1.00, S E \quad .31,95 \%$ CI [ 1.691, 0.447]; dichotomous agreement with climate change science measure, $b \quad 1.01, S E \quad .43,95 \%$ CI [ 2.011, 0.360]. For Democrats, we observed no significant indirect effect of economic beliefs on climate change for either measure (both CIs contained zero): continuous likelihood measure, $b \quad .25, S E \quad .17,95 \%$ CI [ .636, .039]; dichotomous agreement measure, $b \quad .25, S E$ $.21,95 \%$ CI [ .748, .052]. In other words, Republican participants thought the government regulation solution would exert more negative consequences on the economy than would the free market solution, and this in turn led to their increased skepticism toward climate change science. This solution aversion pattern was absent for Democrat participants.

Integrated beliefs. Using this variable, we first assessed whether policy solution had an effect on participants' tendency to hold the integrated belief that climate change was real, was caused by humans, and could be fixed by humans (that is, selecting 1 vs. $2-5$ on the integrated beliefs measure). Republicans were more likely to hold this integrated belief when the policy was free market friendly than when it was not $(64 \%$ vs. $17 \%),{ }^{2}(1, N$ 40) $\quad 8.94, p \quad .003$. Democrats showed no significant difference $(80 \%$ vs. $84 \%), \quad{ }^{2}(1, N \quad 81) \quad 0.24, p \quad .625$.

Next, we assessed whether policy solution had an effect on participants' tendency to hold the integrated belief that climate change was real and caused by humans, which would indicate full agreement with the climate change science statement presented to participants (coded as selecting 1-2 vs. 3-5). Republicans were more likely to hold this integrated belief when the policy was free market friendly than when it was not (68\% vs. $33 \%),{ }^{2}(1, N$ 40) $4.82, p \quad$.028. Democrats showed no significant difference (93\% vs. $92 \%), \quad{ }^{2}(1, N \quad 81) \quad 0.05, p \quad .825$.

These findings suggest that even when people are given the opportunity to distinguish between their beliefs regarding climate change, human involvement, and solution efficacy, a solution aversion effect regarding denial of humankind created climate change still occurs.
Good or bad solutions. This measure mirrors the economic impact of solutions measure. We conducted a 2 (party: Democrat vs. Republican) 2 (policy solutions: government regulation vs. free market friendly) ANOVA on the measure. There was a significant main effect of party affiliation, such that Democrats $(M$ $1.59, S D \quad 1.07)$ compared to Republicans $(M \quad 0.23, S D \quad 1.79)$ reported more favorable opinions of the solutions, $F(1,117)$ $31.79, p \quad .001, \quad 2 \quad .20$, and a main effect of solution, such that those who saw the free market friendly solution $\left(\begin{array}{ll}M & 1.38 \text {, }\end{array}\right.$ $S D$ 1.27) compared to those who saw the government regulation solution $(M \quad 0.85, S D \quad 1.68)$ reported more favorable opinions of the solutions, $F(1,117) \quad 8.36, p \quad .005, \quad 2$ .051 .

Of importance, this analysis also revealed the predicted interactive pattern, $F(1,117) \quad 5.37, p \quad .022,2 \quad .031$. Republicans said the solutions were better ideas when the solutions were free market policy $(M \quad 0.82, S D \quad 1.70)$ than when they were regulatory policy $(M \quad 0.50, S D \quad 1.65), F(1,117) \quad 10.119$, $p \quad .002,2 \quad .061$. Democrats' beliefs about the quality of the ideas, on the other hand, did not significantly vary across condition: free market friendly policy, $M \quad 1.48, S D \quad 1.37$; regulatory policy, $M \quad 0.92, S D \quad 1.72, F(1,117) \quad .25, p \quad .618, \quad 2$ .002 . We conducted the same moderated mediation from above on the effect of policy through opinion about the solutions, conditional on party, on the continuous likelihood measure and separately on the dichotomous climate change science agreement measure. As with the economic beliefs measure, these analyses revealed a significant indirect effect of opinions about the solutions for both climate belief measures for Republicans (continuous likelihood measure, $b \quad .89, S E \quad .34,95 \%$ CI [ $1.564, .218]$; dichotomous agreement measure, $b \quad .84$, $S E \quad .48,95 \%$ CI $[2.01, .139])$ but not for Democrats (continuous likelihood measure, $b \quad .10, S E \quad .16,95 \%$ CI [ $\quad .449$, .212]; dichotomous agreement measure, $b \quad .09, S E \quad .18,95 \%$ CI $[.509, .231])$. That is, once again, increased skepticism toward climate change science is mediated by solution aversion for Republicans but not for Democrats. 


\section{Discussion}

These findings provide a robust combination of experimental and correlational support that Republicans' skepticism toward climate change science is linked to beliefs about the policy solutions. Further, the findings indicate that when the policy solutions of climate change are made salient, solutions that favor a more free market policy approach rather than the more popularly discussed restrictive policy approach may lead Republicans to be less skeptical of the available climate change science.

\section{Study 3}

Thus far, we have observed both correlational and experimental support for our solution aversion explanation of the political divide in climate science. The patterns of the evidence presented cannot be explained by alternative hypotheses - such as party differences in baseline exposure to the climate change science, fear sensitivity, or baseline faith in science-which would predict a consistent skepticism in climate science on the part of Republicans rather than a dissipation of skepticism when the associated solutions are manipulated. In Study 3, we sought to expand upon this line of inquiry in three ways.

First, we isolated the effect of ideology further. If specific ideological beliefs - such as faith in the free market - can drive skepticism in climate beliefs, then even within self-identified Republicans we should observe (a) that belief in climate science varies by the strength with which Republicans endorse this belief and (b) belief in climate science interacts with manipulations of the solution that threaten this specific ideological belief.

Second, for the sake of breadth we sought to examine a different environmental problem (the health effects of air pollution) to test that there was not something unique about how the climate change issue interacted with ideology.

Third, we measured the denial of the scientific statistic in a more direct way. Instead of categorizing a continuous variable, we specifically asked people whether they believe that the factual reality of the air pollution is not as numerically as high as the statistic suggested (that 44 million Americans live in an area burdened by deadly particle pollution) or that the factual reality of the statistic was correct or even higher.

\section{Method}

Participants. One hundred twenty self-identified Republicans completed the survey (male 70, female 49, Decline to State/Other $\quad 1, M_{\text {age }} 31.64$ years, $\left.S D \quad 9.95\right)$ and were paid $\$ 0.45$. Participants were recruited on Amazon Mechanical Turk and let into this survey only if they reported their political affiliation was Republican at the beginning of the survey (other participants were redirected to an unrelated survey).

Procedure and materials. First, we assessed participants' free market ideology. All participants first read the passage about the free market from Study 1 and answered the same two ques-

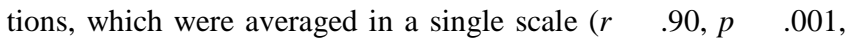
M 79.08, SD 18.89).

All participants then read a blog about a solution to the problem of air pollution, especially due to cars (full stimuli are available in the supplemental materials). In the free market friendly condition, the blog mentioned how the free market could be used to reduce the problem. For instance, it stated, "The solution is the free market... We need to make the public aware of the car pollution problem so the free market can work its magic through customer demands." In the government regulation condition, the blog mentioned how government regulation was needed to solve the problem. For instance, it stated, "The government must step in to reduce pollution . . . include a restriction on car manufacturers that would require them to reduce pollution. Even if the solution was somewhat costly to the manufacturer, they would still be required to implement it."

Participants were then told the blog was in response to a recent statement by the American Lung Association estimating that "44 million people live in an area burdened year-round by unhealthful levels of deadly particle pollution." This statistic was taken from an American Lung Association website official report (State of the Air, 2013).

Next, participants responded to the trichotomous agreement variable. Participants were asked what they thought of the 44 million estimate, and they responded by selecting one of three statements: "Probably not, that is probably an exaggeration," "Probably yes," and "It is probably even worse than 44 million" (the last option was not often chosen; 13\%). We coded participants who indicated "probably not" as denying and the rest of the participants as agreeing, thus converting this trichotomous measure into a dichotomous measure.

Last, participants filled out a continuous measure similar to that in Studies 1 and 2. In this study participants were asked, "What is the likelihood that an American living in an urban city would develop health complications due to pollution?" Answers were made on an 8-point scale from No chance to Certainly.

\section{Results and Discussion}

We hypothesized that denial of the problem of air pollution would vary as a function of both endorsement of free market ideology and the solution.

Continuous measure of likelihood of health problems. First, we assessed these predictions in the context of the continuous measure of developing health problems. We conducted a linear regression of the continuous measure of likelihood to develop health problems on blogger condition (dummy coded 1 for free market friendly), self-reported strength of free market ideology, and their interaction. As presented in Figure 3, this revealed the predicted interactive pattern, $b \quad .02, t(116) \quad 1.20, p \quad .048$. When the solution was government regulation, those with a stronger free market ideology were less likely to believe there was a high health risk, $b \quad .02, t(116) \quad 2.89, p \quad .005$. When the solution was free market friendly, however, individual differences in free market ideology no longer predicted increased skepticism, $b \quad .003, t(116) \quad 0.38, p \quad .708$. We also examined the effect of the solution at higher and lower levels of personal free market ideology following procedures outlined by Aiken and West (1991). As hypothesized, among those who strongly held a free market ideology (1 $S D$ above the mean), belief in a health risk was higher when the solution was free market friendly than when it was not, $b \quad .83, t(116) \quad 2.98, p \quad .003$. Among those who did not strongly hold a free market ideology ( $1 S D$ below the mean), belief 


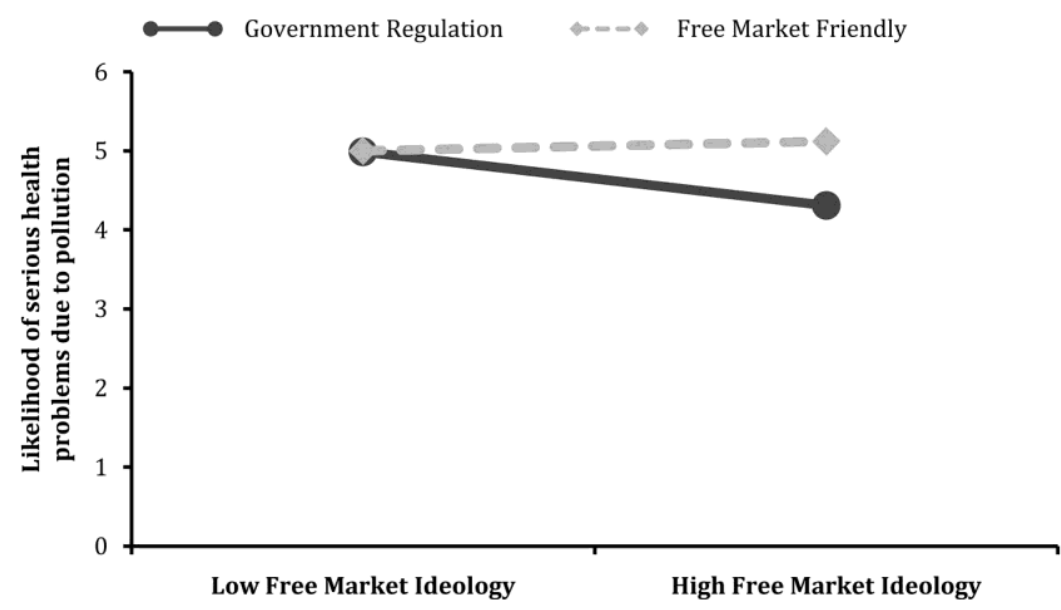

Figure 3. Likelihood of developing a health problem due to pollution as a function of the proposed solutions and strength of free market ideology (Study 3). Only Republicans were recruited for this study. Participants who supported free market ideology relatively more (1 $S D$ from the mean) reported a higher likelihood of health problem as a function of solution, whereas participants who supported free market ideology relatively less ( 1 $S D$ from mean) did not report a significant difference in likelihood by solution.

in a health risk did not significantly differ by whether or not the solution was free market friendly, $b \quad .01, t(116) \quad 0.02, p \quad .98$.

Dichotomous measure of (dis)agreement. Second, we tested the same hypotheses in the context of the dichotomous measure of agreement with the environmental science. We conducted a binary logistic regression of agreement on solution condition (dummy coded 1 for free market friendly), self-reported strength of free market ideology, and their interaction. We once again observed the predicted interactive pattern, $b \quad .07$, Wald $\quad{ }^{2}(1) \quad 5.98, p \quad .014$ (see Figure 4). When the solution was governmental regulation, those with a stronger free market ideology were less likely to agree with the environmental science, $b \quad .04$, Wald ${ }^{2}(1) \quad 5.95$, $p \quad .015$. When the solution was free market friendly, however, the strength of free market ideology did not significantly influence agreement with the environmental science, $b \quad .03$, Wald ${ }^{2}(1)$ $1.40, p \quad .237$. We also examined the effect of the solution at higher and lower levels of personal free market ideology. As hypothesized, among those who strongly held a free market ideology (1 $S D$ above the mean), there was significantly more agreement with the environmental science when the solution was free market friendly than when it was not, $b \quad 2.89$, Wald ${ }^{2}(1)$ $16.65, p \quad .001$. Among those who did not strongly hold a free market ideology (1 $S D$ below the mean), their agreement with the environmental science did not significantly differ based on whether or not the solution was free market friendly, $b \quad .35$, Wald $\quad{ }^{2}(1) \quad 0.26, \quad p \quad .611$.

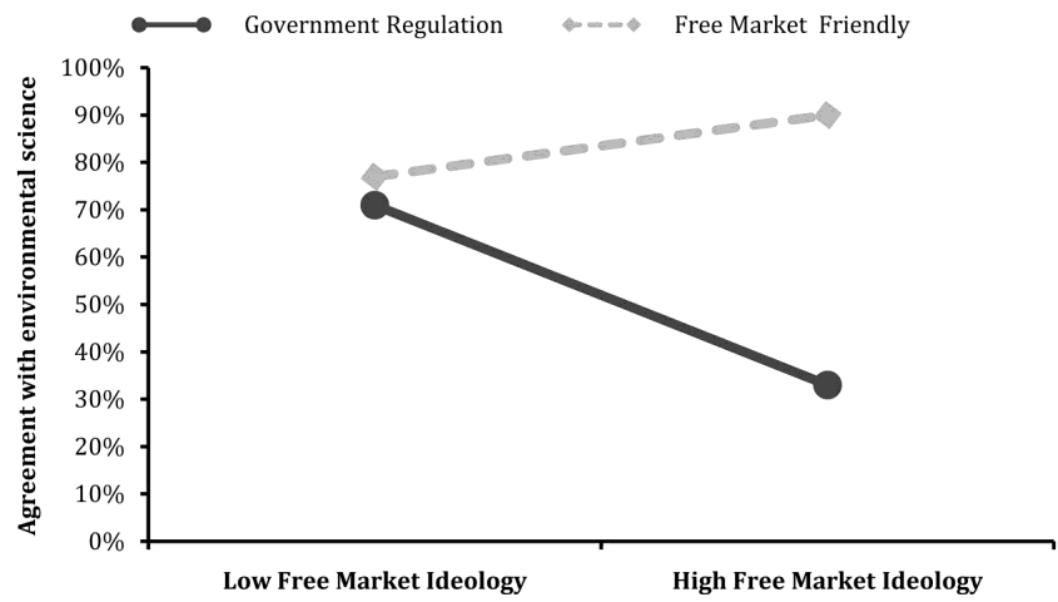

Figure 4. Agreement with environmental science on pollution as a function of the proposed solutions and strength of free market ideology (Study 3). Only Republicans were recruited for this study. Agreement was measured dichotomously; indicating the severity of pollution was at or above the environmental science estimate provided was coded as agreement. Participants who supported free market ideology relatively more (1 SD from the mean) reported higher agreement as a function of solution, whereas participants who supported free market ideology relatively less ( $1 S D$ from mean) did not report a significant difference in agreement by solution. 
These findings provide further evidence for the solution aversion hypothesis. Among Republican participants - that is, those who showed the motivated effects in both of the previous two studies - belief in the existence of environmental science varied as a function not only of the solution but also of the strength of their strength free market ideology. This isolates the role of ideology beyond simple party affiliation.

\section{Study 4}

In Studies 1 through 3, consistent with our solution aversion hypothesis, Republicans showed motivated skepticism of environmental statistics as a function of the extent to which the solutions threatened their ideology. This solution aversion tendency, however, should not be unique to Republicans and conservative ideologies or adherents. That is, if a problem existed for which the associated solutions strongly threatened individuals with a liberal ideology (i.e., desire for gun control), we should observe solution aversion on the part of these individuals. We test this hypothesis in Study 4.

Beyond looking at solution aversion tendencies in those with more a more liberal ideology, we made three additional changes in Study 4 to broaden our perspective. First, we examined a problem unassociated with the environment: criminal activity. Second, we looked at more general beliefs about the severity of the problem, rather than whether it is occurring or not. And third, we used both a dichotomous and a continuous measure of ideology (i.e., our predictor variable) in the same experimental design instead of one or the other as we did in Study 2 and Study 3.

Participants. One hundred ninety-eight participants completed a survey on Amazon Mechanical Turk (male 126, female $\quad 72, M_{\text {age }} \quad 32.95$ years, $S D \quad 11.01$ ) and were paid $\$ 0.45$.

Procedure and materials. Participants first indicated their stance on gun control from three options: "I am in favor of protecting gun ownership rights," "I am in favor of stricter gun control and restrictions on gun ownership," and "Other/No Opinion." This gave us our primary dichotomous predictor variable of gun control supporters and gun-rights supporters.

Next we assessed the gun control ideology of all 198 participants on two continuous measures $(r \quad .70, p \quad .001)$ that we combined into a two-item scale. Participants indicated how much they agreed with two statements on 6-point scale from Not At All to Strongly Agree: "The United States should protect citizens' right to own guns" and "The United States should have stronger gun control laws and more restrictions on gun purchases" (reverse coded). Participants were then told they would read about the topic of "Intruder violence - the act of breaking into a home and attacking the resident, usually as part of a robbery. Intruder violence often ends in the death or injury of the resident."

On the next page of the survey, participants were randomly assigned to one of two solution conditions (see the supplemental materials for full stimuli). In the anti-gun control condition, participants were told they would read an article arguing that "strict gun control laws prevent homeowners from getting guns that they could use to protect themselves from intruder violence" and then read an article espousing this pro-gun rights ideal. In the gun control friendly condition, participants were told they would read an article arguing that "loose gun control laws lead to more gun violence by intruders and more homeowner deaths" and then read an article espousing this pro-gun control ideal.
Over the next three pages participants answered three questions about the severity of the problem of intruder violence. These three questions were presented in a fixed order and were averaged into a single $z$-score standardized scale ( $\quad .77, M \quad 3.18, S D \quad 1.57$ ). Participants first indicated how much they agreed with the statement "There is an epidemic of intruder violence in the United States" on a 7-point scale (Not At All Agree to Strongly Agree). Next, participants indicated how much they agreed with the statement "In general, intruder violence is rare, so we should not be very worried about it" on a 6-point scale (reverse coded; Not At All Agree to Strongly Agree). Finally, participants responded to the question "How much should the average American be worried about intruder violence?" on a 6-point scale (Not At All Worried to Very Worried).

\section{Results}

We first conducted tests of whether the manipulations of associated solutions differentially affected those who indicated they were a supporter of gun rights differently than those who indicated they were supporters of gun control. We then conducted the same tests with the continuous measure of gun control ideology with all participants.

A 2 (ideology: gun rights supporter vs. gun control supporter) 2 (policy solutions: anti-gun control vs. gun control friendly) ANOVA was conducted on the severity of intruder violence measure. There were significant main effects of both gun control stance and solution, such that gun control supporters $\left(\begin{array}{lll}M & .10, S D & .78\end{array}\right)$ compared to gun rights supporters $\left(\begin{array}{lll}M & .16, S D & .87\end{array}\right)$ were less likely to report the problem as severe, $F(1,174) \quad 5.04, p \quad .026, \quad 2 \quad .042$, and those who saw anti-gun control policy $\left(\begin{array}{llll}M & .13, S D & .83\end{array}\right)$

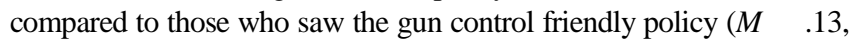
$S D \quad .80)$ were less likely to report the problem was severe, $F(1$, 174) $8.39, p \quad .004, \quad 2 \quad .025$.

Of importance, the analysis also revealed the predicted interactive pattern, $F(1,174) \quad 11.66, p \quad .001, \quad 2 \quad .059$ (see Figure 5 ). To explore this interaction, we tested the effect of policy solutions separately for each group. Self-identified gun control supporters reported a significantly higher severity of the intruder violence problem when the policy solution was gun control friendly $\left(\begin{array}{lll}M & .21, S D & .77\end{array}\right)$ than when the solution was anti-gun control $(M \quad .55, S D \quad .80), F(1,174) \quad 16.42, p \quad .001, \quad 2$ .082. Self-identified gun rights supporters, however, reported directionally lower severity of the intruder violence problem when the policy solution was gun control friendly $\left(\begin{array}{lll}M & .07, S D & .82\end{array}\right)$ than when it was anti-gun control $\left(\begin{array}{lll}M & .13, S D & .74\end{array}\right), F(1$, 174) $\quad 0.17, p \quad .681,2 \quad .001$.

Next, we assessed these predictions with the complete sample using the continuous gun control ideology measure, in which higher ratings indicated a stronger preference for gun control ideology. That is, we conducted a linear regression of the severity of intruder violence scale (dummy coded as 1 for gun control friendly), self-reported gun control ideology, and their interaction. As presented in Figure 6, this revealed the predicted interactive pattern, $b \quad .17, t(194) \quad 2.29$, $p \quad .023$. When the solution was anti-gun control, those with a higher gun control ideology were less likely to believe there was a severe intruder violence problem risk, $b \quad .14, t(194) \quad 2.79, p \quad .006$. When the solution was gun control friendly, however, those with a higher gun control ideology were directionally more likely to believe there was a severe intruder violence problem health risk, $b \quad .03$, $t$ (194) $\quad 0.49, p \quad .628$. We also examined the effect of the blogger's 


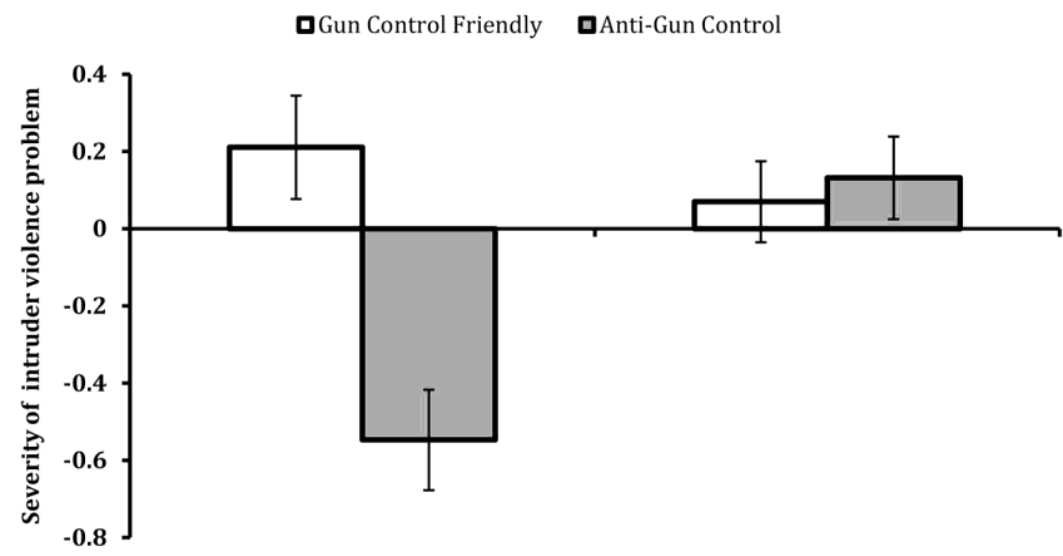

Gun Control Supporters

Gun Rights Supporters

Figure 5. Severity of intruder violence as a function of self-reported supporter status (gun control or gun rights) and proposed policy solutions (Study 4). Only participants who selected into gun rights supporter or gun control supporter were analyzed. The dependent variable is $z$-score standardized, and error bars reflect the estimated least squared standard errors for the $z$ score. Solution had a significant effect only on gun control supporters.

solution at higher and lower levels of support for gun control (following procedures outlined by Aiken \& West, 1991). As hypothesized, those who strongly held a gun control ideology (1 SD above the mean) indicated a higher belief in the severity of intruder violence when the solution was gun control friendly than when it was not, $b$ $.45, t(194) \quad 2.79, p \quad .006$. Those lower on gun control ideology (1 $S D$ below the mean), indicated a directionally lower belief in the severity of intruder violence when the solution was gun control friendly than when it was not, $b \quad .08, t(194) \quad 0.49, p \quad .640$.

\section{Discussion}

Together these, findings provide evidence for solution aversion outside of the environmental domain and among participants high in an ideology that is not conservative. Though we did not observe a significant solution aversion pattern for those who advocated gun right ownership, the overall interaction pattern and the specific effects for those who held the more liberal, gun right restriction ideology were all significant and consistent with a solution aversion prediction. Polling data tend to show that the majority of those who favor gun ownership rights also tend to favor some measures of gun control (Drake, 2014), so for those supportive of gun ownership rights, the gun control friendly condition may not have seemed especially aversive. This may also be the case for those with more liberal economic ideologies in the environmental studies. Because they may not be strongly anti-free market, they may not react strongly to suggestions of free market solutions.

\section{General Discussion}

Across four studies, we provide triangulating support for a solution aversion model in the domain of environmental science and demonstrate breadth in a second domain. These data suggest that skepticism toward issues such as climate change and environmental science may

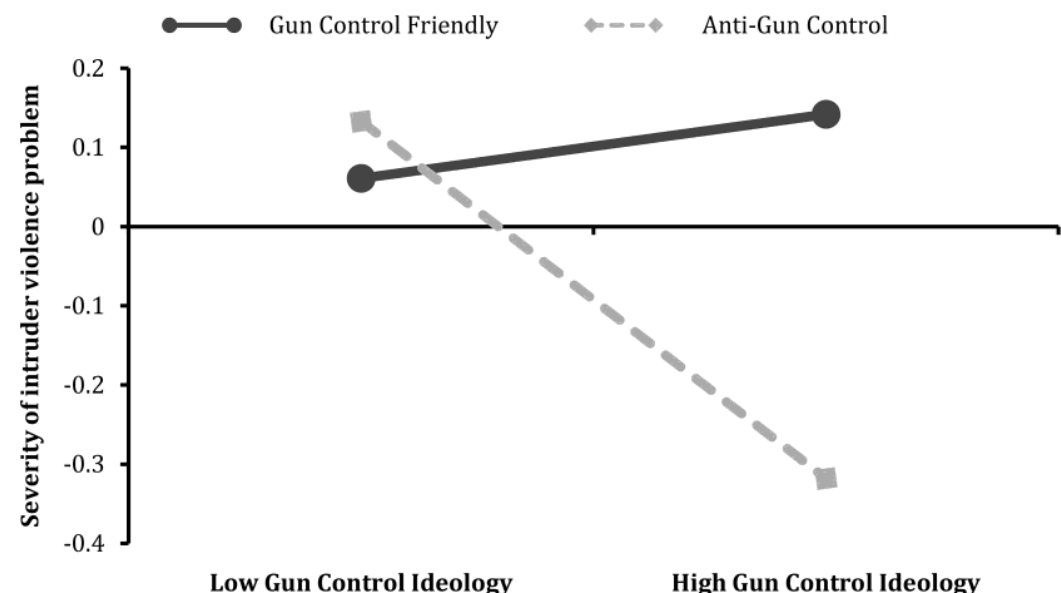

Figure 6. Severity of intruder violence as a function of self-reported gun control ideology and proposed policy solutions (Study 4). All Study 4 participants were analyzed. The dependent variable is $z$-score standardized. Solution had a significant affect only on those higher in gun control ideology. 
be caused in part by the unique implications climate change solutions hold for certain individuals' ideological values, rather than just simply a blanket tendency for certain individuals or groups to dislike science or deny catastrophe and problems. This process distinction is important, because it suggests not only a novel trigger of motivated cognition (i.e., the solutions associated with problems, rather than the problems themselves) but also a more sophisticated way to approach interventions aimed at abating scientific skepticism.

\section{Relation to Past Environmental Skepticism Research}

Locating much of our investigation in the specific context of environmental science offered us a unique opportunity not only to highlight an underappreciated form of motivated cognition but to do so in a way illustrates its incremental value in explaining an important social problem. Climate change and other environment issues are considered massive world problems that need "miracle" solutions (Gates, 2010), and belief in climate change seems to be highly associated with ideological beliefs (Pew Research Center, 2010). Many hypotheses have been put forward to explain the divide over climate and environmental sciences, such as differential exposure to media, differential trust in science, or differential fear sensitivity between the parties (Carraro et al., 2011; Jost et al., 2003; Oxley et al., 2008). The solution aversion model proposed here offers an additional and novel perspective to this growing literature, one that we suggest holds important societal implications. Indeed, the small manipulations in our studies produced striking and dramatic effects: reducing or entirely erasing ideological line differences in environmental skepticism and shifting rates of agreement nearly $40 \%$.

The current findings also help clarify and organize past research on how values and fears are related to beliefs, including environmental and climate change beliefs (Feinberg \& Willer, 2011, 2013; Feygina et al., 2010; Hardisty, Johnson, \& Weber, 2010; Lewandowsky, Oberauer, \& Gignac, 2013; McCright \& Dunlap, 2011a, 2011b). For example, Schuldt et al. (2011) have observed that Republicans, but not Democrats, are more likely to indicate that they believe in climate change when it is phrased as "climate change" rather than "global warming." One possible mechanism for this finding, given the data we have presented here, may be that the term global warming holds a stronger cognitive association with dramatic policy solutions than the more contemporary phrase climate change. This could be because it sounds more dire, making specific large-scale policy interventions feel more likely, given that such policy interventions have become linked to climate change through political rhetoric and media coverage. It is also possible (and potentially likely) that both fear of the problem and aversion to the solutions motivated skepticism.

Or consider a study from the Pew Research Center (2010) that found Tea Party Republicans are much more likely to state there is no solid evidence that average temperatures on earth are warming than are Republicans who disagree with the Tea Party platform (respectively, $70 \%$ vs. $38 \%$ ). Given that the Tea Party is characterized by an ideology that strongly prioritizes the free market and rejects government regulation, this finding makes good sense from a solution aversion perspective. Put simply, Tea Party Republicans may very well hold an ideology that is more acutely threatened by climate change solutions. The findings presented in our third study, which isolate the precise role of free market ideology in driving solution aversion effects specifically within a sample of Republicans, suggest this may very well be the case.

Other research suggests interesting potential moderators for the findings we have presented. For example, Lewandowsky, Gignac, and Vaughan (2013) have noted the pivotal role of perceived scientific consensus in driving climate change beliefs. It is certainly possible that arguments that degrade perceived scientific consensus allow solution aversion effects to manifest. And, conversely, it is also possible that if perceived scientific consensus was strong enough, solution aversion effects would be muted. That said, it also seems feasible to us that solution aversion processes themselves may shape perceptions of scientific consensus, making the relation essentially bidirectional.

Finally, our findings build upon and extend past experimental work that has examined the influence of psychological motivations on environmental behaviors and climate change beliefs (Feinberg \& Willer, 2011, 2013; Feygina et al., 2010; Hardisty et al., 2010; Kahan, Jenkins-Smith, Tarantola, Silva, \& Braman, 2012). A number of studies have examined how certain psychological motives and needs can affect climate change science skepticism. Feinberg and Willer (2011), for example, observed that belief in a just world motivates skepticism of climate change, especially when consequences seem dire and thus contradict the existence of a just world. The model and data presented here suggest that those high in just world belief might not only be reticent to acknowledge fundamental problems with the world-because, as Feinberg and Willer noted, doing so suggests an unjust world-but may also be averse to the policy solutions associated with these problems. This is especially so given that government regulation naturally undermines the belief that people are largely responsible for their own actions - a core tenet of the belief in a just world (Lerner, 1980).

\section{Limitations}

The most obvious limitation of this set of studies is the reliance on online convenience samples (i.e., Mechanical Turk). Though samples such as these have been shown to be as effective at capturing psychological phenomenon as are traditional convenience samples (i.e., student populations; Behrend, Sharek, Meade, \& Wiebe, 2011; Berinsky, Huber, \& Lenz, 2012; Paolacci, Chandler, \& Ipeirotis, 2010), two concerns that have recently been raised with these types of samples are worth discussing here. First, it has been noted that, without the proper procedures, these samples may include an abundance of participants who either are devoting little attention or who have previously partaken in the same or a very similar study (Chandler, Mueller, \& Paolacci, 2014). Though it is impossible to avoid some degree of these problems, we took several measures to ensure both that our participants were new to our experiments and that they paid a sufficient degree of attention. To this end, following suggestions of prior literature, participants were excluded prior to entry into the main survey if they had already taken an online survey on the topic with our lab, had failed a reading attention check, or had the same IP address as a prior participant (Chandler et al., 2014; Peer, Vosgerau, \& Acquisti, 2013).

Second, it has been suggested (Kahan, 2013) that in samples such as these, self-identified partisan respondents (i.e., Republicans) may be atypical members of their political party. To the extent this is so, this would limit the external validity of our findings regarding specific cases of solution aversion. Although we acknowledge that the Re- 
publicans and Democrats in our sample are not going to be perfectly representative of the larger population, the key reason we wanted to sample Republicans and Democrats was their differing views on the issues of climate change and economics. Across our studies, the self-identified Republicans and Democrats we sampled did appear to substantially differ in their views on these two key dimensions in ways consistent with prior representative public samples (Pew Research Center, 2010, 2012). In addition, though a goal of ours was to study solution aversion in an impactful context (i.e., climate change), our primary goal was to demonstrate the existence of this psychological phenomenon.

For these reasons, we feel our samples are adequate for our goals. That said, there is no question that replications of our studies in more representative samples are important, especially if we hope to understand the degree to which solution aversion predicts actual levels of climate science denial in the general population.

\section{Relation to Other Theoretical Models}

System justification theory. System justification (Jost \& Banaji, 1994) is the tendency for people to justify, maintain, and otherwise bolster the validity of their current social system, often through motivated and fact-defying processes. Given that system justification tendencies can be engendered by threat (Jost, Kivetz, Rubini, Guermandi, \& Mosso, 2005; Kay, Jost, \& Young, 2005) and that acknowledging failures of the system that are especially dramatic is incompatible with the system justification motive (Brescoll, Uhlmann, \& Newman, 2013; Napier, Mandisodza, Andersen, \& Jost, 2006), it is easy to imagine how climate change denial might relate to system justification motives. And, in fact, system justification motives have been shown to predict skepticism toward climate change (Feygina et al., 2010). The current research suggests that beyond the ways in which acknowledging climate change, in and of itself, is problematic from a system justification perspective, so too might be the solutions associated with climate change. This could occur for one of two reasons.

First, to the extent people associate government intervention and limits on freedom as a viable solution to climate change, they are necessarily challenging the legitimacy of one of the most powerful system justifying ideologies: meritocracy (Jost et al., 2003; Major, 1994). Many people strongly believe that government intervention necessarily limits meritocracy, at least in its purest form, and so supporting government intervention is at odds with motives that are satiated by supporting ideologies of meritocracy (also see Sidanius \& Pratto, 1999). Second, any radical change to government policy that is enacted as a solution, whatever its content, should be challenging to people's system justification motive. As such, to the degree that climate change solutions are considered "radical" or "unprecedented," they will necessarily encounter resistance, especially when motives to legitimize the status quo are salient (Kay \& Zanna, 2009). Consistent with this, Feygina et al. (2010) observed that not only are system justification motivations predictive of skepticism toward climate change, but that when climate change solutions are positioned as system sanctioned (i.e., a means of protecting the status quo), system justification no longer motivates skepticism.

Coherence. Solution aversion may also be at least in part a product of people's general tendency to seek cognitive coherence (Osgood \& Tannenbaum, 1955; Simon, 2004; Simon, Krawczyk, Bleicher, \& Holyoak, 2008). As Simon, Snow, and Read (2004) explained, "Coherent representations are ones in which elements that are positively related to one another tend to wax and wane together" (p. 816). In the case of the current climate experiments, it would be highly incoherent to be averse to and nonsupportive of environmental solutions but also believe in the environmental problem, insofar as the belief in the problem may more or less imply the enactment of the specific solutions.

Of particular relevance is recent research on moral coherence (Ditto \& Liu, 2011). Though it might be tempting to assume that issues such as capital punishment (or hypothetical problems like the trolley problem) may force people into moral dilemmas between what they know factually (e.g., the efficacy of using capital punishment to reduce crime) and what they believe deontologically (e.g., it is wrong to kill a defenseless person), Liu and Ditto (2013) suggest this rarely occurs. Instead, people usually find ways to shape their factual beliefs so that these are largely consistent with their moral beliefs, thus minimizing any psychological dilemma. For instance, participants who first experienced a manipulation designed to alter their moral beliefs surrounding capital punishment subsequently also changed their factual beliefs about the efficacy of capital punishment to cohere with their new moral beliefs, despite not being exposed to any new factual information between conditions. In the case of solution aversion, a similar coherence-driven process may also be at work, though it might need to unfold in a slightly more complicated way, whereby coherence motives do not just lead people to reconstrue the efficacy of a solution that is misaligned with their values but also (perhaps retroactively) to reconstrue the problem that originally necessitated the solution.

In short, then, although the solution aversion model proposed and tested here offers a novel perspective, it does so in a way that also complements much previous theory and research. This is true, we believe, for both the field of motivated cognition generally and the important domain of climate science attitudes more specifically. By using the political divide over climate change to test a novel process of motivated cognition, we have hopefully not only provided evidence for a novel form of motivated cognition, but also shed new light on why and how political ideology can lead to divided attitudes toward pressing social and scientific problems.

\section{References}

Abramowitz, A. I., \& Saunders, K. L. (2006). Exploring the bases of partisanship in the American electorate: Social identity vs. ideology. Political Research Quarterly, 59, 175-187. doi:10.1177/106591290605900201

Aiken, L. S., \& West, S. G. (1991). Multiple regression: Testing and interpreting interactions. Newbury Park, CA: Sage.

Babiker, M. H., \& Eckaus, R. S. (2002). Rethinking the Kyoto emissions targets. Climatic Change, 54, 399-414. doi:10.1023/A:1016139500611

Behrend, T. S., Sharek, D. J., Meade, A. W., \& Wiebe, E. N. (2011). The viability of crowdsourcing for survey research. Behavior Research Methods, 43, 800-813. doi:10.3758/s13428-011-0081-0

Berinsky, A. J., Huber, G. A., \& Lenz, G. S. (2012). Evaluating online labor markets for experimental research: Amazon.com's Mechanical Turk. Political Analysis, 20, 351-368. doi:10.1093/pan/mpr057

Brescoll, V. L., Uhlmann, E. L., \& Newman, G. E. (2013). The effects of system-justifying motives on endorsement of essentialist explanations for gender differences. Journal of Personality and Social Psychology, 105, 891-908. doi:10.1037/a0034701

Carney, D. R., Jost, J. T., Gosling, S. D., \& Potter, J. (2008). The secret lives of liberals and conservatives: Personality profiles, interaction 
styles, and the things they leave behind. Political Psychology, 29, 807-840. doi:10.1111/j.1467-9221.2008.00668.x

Carraro, L., Castelli, L., \& Macchiella, C. (2011). The automatic conservative: Ideology-based attentional asymmetries in the processing of valenced information. PLoS ONE, 6(11), e26456. doi:10.1371/journal .pone. 0026456

Chandler, J., Mueller, P., \& Paolacci, G. (2014). Nonnaïveté among Amazon Mechanical Turk workers: Consequences and solutions for behavioral researchers. Behavior Research Methods, 46, 112-130. doi:10.3758/s13428013-0365-7

Cook, J., Nuccitelli, D., Green, S. A., Richardson, M., Winkler, B., Painting, R., . . Skuce, A. (2013). Quantifying the consensus on anthropogenic global warming in the scientific literature. Environmental Research Letters, 8, Article 024024. doi:10.1088/1748-9326/8/2/024024

Cunningham, P. (2012, September 10). Here's more stuff for the antiscience Republicans to deny [Blog post]. Retrieved from http://blogs.erockford.com/applesauce/2012/09/10/heres-more-stuff-for-the-antiscience-republicans-to-deny/

Cutting, H. (2013, January 22). The no-spin zone on climate change [Blog post]. Retrieved from http://www.huffingtonpost.com/hunter-cutting/ climate-change-politics_b_2511828.html

Ditto, P. H., \& Liu, B. (2011). Deontological dissonance and the consequentialist crutch. In M. Mikulincer \& P. Shaver (Eds.), The social psychology of morality: Exploring the causes of good and evil (pp. 51-70). Washington, DC: American Psychological Association.

Ditto, P. H., \& Lopez, D. F. (1992). Motivated skepticism: Use of differential decision criteria for preferred and nonpreferred conclusions. Journal of Personality and Social Psychology, 63, 568-584. doi:10.1037/ 0022-3514.63.4.568

Drake, B. (2014, April 24). Five facts about the NRA and guns in America. Retrieved from http://www.pewresearch.org/fact-tank/2014/04/24/5facts-about-the-nra-and-guns-in-america/

Feinberg, M., \& Willer, R. (2011). Apocalypse soon? Dire messages reduce belief in global warming by contradicting just-world beliefs. Psychological Science, 22, 34-38. doi:10.1177/0956797610391911

Feinberg, M., \& Willer, R. (2013). The moral roots of environmental attitudes. Psychological Science, 24, 56-62. doi:10.1177/0956797612449177

Feygina, I., Jost, J. T., \& Goldsmith, R. E. (2010). System justification, the denial of global warming, and the possibility of "system-sanctioned change." Personality and Social Psychology Bulletin, 36, 326-338. doi: $10.1177 / 0146167209351435$

Gates, B. (2010). Talking about energy miracles at TED [Blog post]. Retrieved from http://www.thegatesnotes.com/Topics/Energy/TalkingAbout-Energy-Miracles-at-TED

Gauchat, G. (2012). Politicization of science in the public sphere: A study of public trust in the United States, 1974 to 2010. American Sociological Review, 77, 167-187. doi:10.1177/0003122412438225

GOP.com. (2014). Our party. Retrieved from http://www.gop.com/ourparty/

Gore, A. (2006). An inconvenient truth: The planetary emergency of global warming and what we can do about it. New York, NY: Rodale Press.

Greene, S. (2004). Social identity theory and party identification. Social Science Quarterly, 85, 136-153. doi:10.1111/j.0038-4941.2004 08501010.x

Greenpeace. (2011, April 14). Koch industries: Still fueling climate denial, 2011 update. Retrieved from http://www.greenpeace.org/usa/en/mediacenter/reports/Koch-Industries-Still-Fueling-Climate-Denial-2011-Update/

Grigsby, E. (2008). Analyzing politics: An introduction to political science (5th ed.). Belmont, CA: Wadsworth.

Haidt, J. (2013). The righteous mind: Why good people are divided by politics and religion. New York, NY: Random House.

Hansen, J., Stiglitz, J., Pachauri, R. K., \& Rosenzweig, C. (2008, January 30). How the Nobel was won: Advances in the science of climate change [Panel discussion]. New York, NY: Columbia University.
Hardisty, D. J., Johnson, E. J., \& Weber, E. U. (2010). A dirty word or a dirty world? Psychological Science, 21, 86-92. doi:10.1177/0956797609355572

Hayes, A. F. (2012). PROCESS: A versatile computational tool for observed variable mediation, moderation, and conditional process modeling [White paper]. Retrieved from http://www.personal.psu.edu/jxb14/ M554/specreg/process2012.pdf

Intergovernmental Panel on Climate Change. (2007). Climate change 2007: The physical science basis. Contribution of Working Group I to the fourth assessment report of the Intergovernmental Panel on Climate Change. New York, NY: Cambridge University Press.

Jost, J. T. (2006). The end of the end of ideology. American Psychologist, 61, 651-670. doi:10.1037/0003-066X.61.7.651

Jost, J. T., \& Banaji, M. R. (1994). The role of stereotyping in systemjustification and the production of false consciousness. British Journal of Social Psychology, 33, 1-27. doi:10.1111/j.2044-8309.1994.tb01008.x

Jost, J. T., Blount, S., Pfeffer, J., \& Hunyady, G. (2003). Fair market ideology: Its cognitive-motivational underpinnings. Research in Organizational Behavior, 25, 53-91. doi:10.1016/S0191-3085(03)25002-4

Jost, J. T., Glaser, J., Kruglanski, A. W., \& Sulloway, F. J. (2003). Political conservatism as motivated social cognition. Psychological Bulletin, 129, 339-375. doi:10.1037/0033-2909.129.3.339

Jost, J. T., Kivetz, Y., Rubini, M., Guermandi, G., \& Mosso, C. (2005). System-justifying functions of complementary regional and ethnic stereotypes: Cross-national evidence. Social Justice Research, 18, 305333. doi:10.1007/s11211-005-6827-z

Jost, J. T., Nosek, B. A., \& Gosling, S. D. (2008). Ideology: Its resurgence in social, personality, and political psychology. Perspectives on Psychological Science, 3, 126-136. doi:10.1111/j.1745-6916.2008.00070.x

Kahan, D. (2009). "Ideology in" or "cultural cognition of" judging: What difference does it make? Marquette Law Review, 92, 413-421.

Kahan, D. (2010, January 20). Fixing the communications failure. Nature, 463, 296-297. doi:10.1038/463296a

Kahan, D. (2013, July 10). Fooled twice, shame on who? Problems with Mechanical Turk study samples, part 2 [Blog post]. Retrieved from http://www.culturalcognition.net/blog/2013/7/10/fooled-twice-shameon-who-problems-with-mechanical-turk-stud.html

Kahan, D., Jenkins-Smith, H., Tarantola, T., Silva, C., \& Braman, D. (2012). Geoengineering and the science communication environment: A cross-cultural experiment (Cultural Cognition Project Working Paper No. 92). Retrieved from http://www.climateaccess.org/

Kay, A. C., Jost, J. T., \& Young, S. (2005). Victim derogation and victim enhancement as alternate routes to system justification. Psychological Science, 16, 240-246. doi:10.1111/j.0956-7976.2005.00810.x

Kay, A. C., \& Zanna, M. (2009). A contextual analysis of the system justification motive and its societal consequences. In J. T. Jost, A. C. Kay, \& H. Thorisdottir (Eds.), Social and psychological bases of ideology and system justification (pp. 158-181). New York, NY: Oxford University Press.

Koba, M. (2013). Fighting climate change could come at a high price. CNBC Online: Economy. Retrieved from http://www.cnbc.com/id/ 100398076/Fighting_Climate_Change_Could_Come_at_a_High_Price

Krosnick, J. A., Holbrook, A. L., Lowe, L., \& Visser, P. S. (2006). The origins and consequences of democratic citizens' policy agendas: A study of popular concern about global warming. Climatic Change, 77, 7-43. doi:10.1007/s10584-006-9068-8

Kunda, Z. (1990). The case for motivated reasoning. Psychological Bulletin, 108, 480-498. doi:10.1037/0033-2909.108.3.480

Lerner, M. J. (1980). The belief in a just world. New York, NY: Plenum Press.

Lewandowsky, S., Gignac, G. E., \& Oberauer, K. (2013). The role of conspiracist ideation and worldviews in predicting rejection of science. PLOS ONE, 8(10), e75637. doi:10.1371/journal.pone.0075637 
Lewandowsky, S., Gignac, G. E., \& Vaughan, S. (2013). The pivotal role of perceived scientific consensus in acceptance of science. Nature Climate Change, 3, 399-404. doi:10.1038/nclimate1720

Lewandowsky, S., Oberauer, K., \& Gignac, G. E. (2013). NASA faked the moon landing-Therefore, (climate) science is a hoax: An anatomy of the motivated rejection of science. Psychological Science, 24, 622-633. doi: $10.1177 / 0956797612457686$

Liu, B. S., \& Ditto, P. H. (2013). What dilemma? Moral evaluation shapes factual belief. Social Psychological and Personality Science, 4, 316323. doi:10.1177/1948550612456045

Lord, C. G., Ross, L., \& Lepper, M. R. (1979). Biased assimilation and attitude polarization: The effects of prior theories on subsequently considered evidence. Journal of Personality and Social Psychology, 37, 2098-2109. doi:10.1037/0022-3514.37.11.2098

Major, B. (1994). From social inequality to personal entitlement: The role of social comparisons, legitimacy appraisals, and group memberships. Advances in Experimental Social Psychology, 26, 293-355. doi:10.1016/ S0065-2601(08)60156-2

McCright, A. M., \& Dunlap, R. E. (2011a). Cool dudes: The denial of climate change among conservative white males in the United States. Global Environmental Change, 21, 1163-1172. doi:10.1016/j.gloenvcha .2011 .06 .003

McCright, A. M., \& Dunlap, R. E. (2011b). The politicization of climate change and polarization in the American public's views of global warming, 2001-2010. Sociological Quarterly, 52, 155-194. doi:10.1111/j .1533-8525.2011.01198.x

Napier, J. L., Mandisodza, A. N., Andersen, S. M., \& Jost, J. T. (2006). System justification in responding to the poor and displaced in the aftermath of Hurricane Katrina. Analyses of Social Issues and Public Policy, 6, 57-73. doi:10.1111/j.1530-2415.2006.00102.x

Narula, S. K., Jacobs, R., \& Ohikuare, J. (2013, October 4). 32 Republicans who caused the government shutdown. The Atlantic. Retrieved from http://www.theatlantic.com/

Oreskes, N. (2004, December 3). The scientific consensus on climate change. Science, 306, 1686. doi:10.1126/science. 1103618

Osgood, C. E., \& Tannenbaum, P. H. (1955). The principle of congruity in the prediction of attitude change. Psychological Review, 62, 42-55. doi: $10.1037 / \mathrm{h} 0048153$

Oxley, D. R., Smith, K. B., Alford, J. R., Hibbing, M. V., Miller, J. L., Scalora, M., . . Hibbing, J. R. (2008, September 19). Political attitudes vary with physiological traits. Science, 321, 1667-1670. doi:10.1126/ science. 1157627

Paolacci, G., Chandler, J., \& Ipeirotis, P. G. (2010). Running experiments on Amazon Mechanical Turk. Judgment and Decision Making, 5, 411419.

Peer, E., Vosgerau, J., \& Acquisti, A. (2013). Reputation as a sufficient condition for data quality on Amazon Mechanical Turk. Behavior Research Methods. Advance online publication. doi:10.3758/s13428-0130434-y

Pew Research Center. (2010). Wide partisan divide over global warming. Retrieved from http://www.pewresearch.org/2010/10/27/wide-partisandivide-over-global-warming/
Pew Research Center. (2012). Deepening divide between Republicans and Democrats over business regulation. Retrieved from http://www .pewresearch.org/daily-number/deepening-divide-between-republicansand-democrats-over-business-regulation/

Platform Committee. (2012). We believe in America: 2012 Republican Platform. Retrieved from http://www.presidency.ucsb.edu/ws/ ?pid 101961

Samuelson, D. (2010, August 18). GOP candidates knock global warming. Politico. Retrieved from http://www.politico.com/news/stories/0810/ 41192.html

Schuldt, J. P., Konrath, S. H., \& Schwarz, N. (2011). "Global warming" or "climate change"? Whether the planet is warming depends on question wording. Public Opinion Quarterly, 75, 115-124. doi:10.1093/poq/ nfq073

Sedikides, C., \& Strube, M. J. (1997). Self-evaluation: To thine own self be good, to thine own self be sure, to thine own self be true, and to thine own self be better. Advances in Experimental Social Psychology, 29, 209-269. doi:10.1016/S0065-2601(08)60018-0

Sidanius, J., \& Pratto, F. (1999). Social dominance: An intergroup theory of social hierarchy and oppression. New York, NY: Cambridge University Press.

Simon, D. (2004). A third view of the black box: Cognitive coherence in legal decision making. The University of Chicago Law Review, 71, 511-586. Retrieved from http://ssrn.com/abstract 541263

Simon, D., Krawczyk, D. C., Bleicher, A., \& Holyoak, K. J. (2008). The transience of constructed preferences. Journal of Behavioral Decision Making, 21, 1-14. doi:10.1002/bdm.575

Simon, D., Snow, C. J., \& Read, S. J. (2004). The redux of cognitive consistency theories: Evidence judgments by constraint satisfaction. Journal of Personality and Social Psychology, 86, 814-837. doi:10.1037/00223514.86.6.814

State of the Air. (2013). Key findings from 2009-2011. Retrieved from http://www.stateoftheair.org/2013/key-findings/

Taber, C. S., \& Lodge, M. (2006). Motivated skepticism in the evaluation of political beliefs. American Journal of Political Science, 50, 755-769. doi:10.1111/j.1540-5907.2006.00214.x

Tedin, K. L. (1987). Political ideology and the vote. Research in Micropolitics, 2, 63-94.

Thaler, R. H., \& Sunstein, C. R. (2008). Nudge: Improving decisions about health, wealth, and happiness. New Haven, CT: Yale University Press.

Toner, K., Leary, M. R., Asher, M. W., \& Jongman-Sereno, K. P. (2013). Feeling superior is a bipartisan issue: Extremity (not direction) of political views predicts perceived belief superiority. Psychological Science, 24, 2454-2462. doi:10.1177/0956797613494848

Yam, P. (2012). Fox news distorts climate science; in other news, the Pope is Catholic [Blog post]. Retrieved from http://blogs.scientificamerican .com/observations/2012/09/22/fox-news-distorts-climate-science/ 